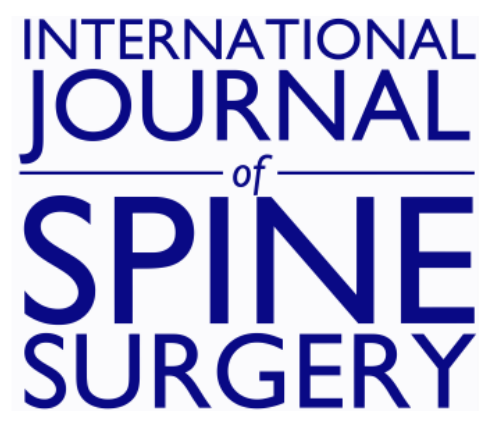

\title{
Comparison of Surgical Outcome Between Diabetic Versus Nondiabetic Patients After Lumbar Fusion
}

KEISAN MOAZZENI, KASRA AMIN KAZEMI, RAMIN KHANMOHAMMAD, MOHAMMAD ESLAMIAN, MOHSEN ROSTAMI and MORTEZA FAGHIH-JOUIBARI

Int J Spine Surg 2018, 12 (4) 528-532

doi: https://doi.org/10.14444/5064

http://ijssurgery.com/content/12/4/528

This information is current as of April 26, 2023.

Email Alerts Receive free email-alerts when new articles cite this article. Sign up at:

http://ijssurgery.com/alerts

The International Journal of Spine Surgery

2397 Waterbury Circle, Suite 1,

Aurora, IL 60504, Phone: +1-630-375-1432 


\title{
Comparison of Surgical Outcome Between Diabetic Versus Nondiabetic Patients After Lumbar Fusion
}

\author{
KEISAN MOAZZENI, MD, ${ }^{1}$ KASRA AMIN KAZEMI, MD, ${ }^{1}$ RAMIN KHANMOHAMMAD, MD, ${ }^{2}$ \\ MOHAMMAD ESLAMIAN, MD,${ }^{1}$ MOHSEN ROSTAMI, MD, ${ }^{3,4}$ MORTEZA FAGHIH-JOUIBARI, MD ${ }^{1}$ \\ ${ }^{1}$ Department of Neurosurgery, Shariati Hospital, Tehran University of Medical Sciences, Tehran, Iran, ${ }^{2}$ Neuroscience Research Centre, Shahid Beheshti University \\ of Medical Sciences, Tehran, Iran, ${ }^{3}$ Brain and Spinal Cord Injuries Research Center, Neuroscience Institute, Tehran University of Medical Sciences, Tehran, Iran, \\ ${ }^{4}$ Sports Medicine Research Center, Tehran University of Medical Sciences, Tehran, Iran.
}

\begin{abstract}
Background: The prevalence of diabetes mellitus (DM) is increasing worldwide. Thereby, an increasing rate of patients with DM are subjecting to spine surgery. Reviewing the literature, a higher rate of surgery-related complications is reported in DM patients. There is no prospective study comparing the outcomes of lumbar fusion surgery in patients with and without DM. We aimed to investigate whether DM is associated with worse patientreported outcomes, lower fusion rate, and higher complication rate in subjects undergoing spinal lumbar fusion surgery.

Methods: Forty-eight subjects with DM (DM group) and 48 controls (control group) were recruited. Data regarding age, duration of diabetes, comorbidities, fasting blood sugar, HbAlc, insulin dependence, duration of operation and the volume of bleeding, and the number of infused packed cell were recorded for all patients. Pain and functional status of the patients using the visual analogue scale (VAS) and Oswestry Disability Index (ODI) were measured before operation and 2 weeks, 6 months, and 1 year after lumbar spinal fusion surgery. Using lumbar computed tomography scan and anteroposterior and lateral x-ray 1 year after the surgery, fusion was assessed.

Results: Fusion rate after 1 year was $78 \%$ in the control group and $53 \%$ in the DM group $(P=.02)$. Patients with DM had higher VAS scores comparing to controls 1 year after the operation, but the difference was not significant $(P=$ .07). However, comparing the functional status of the subjects, significantly higher ODI scores were found among DM patients comparing to controls $(P=.002)$.

Conclusion: Rate of fusion among diabetic patients who undergo lumbar spinal fusion surgery is lower than healthy controls. Spine surgeons should consider this to provide the best possible facilities during the surgery to increase the fusion rate in these patients.

Lumbar Spine

Keywords: lumbar, fusion, diabetes
\end{abstract}

\section{INTRODUCTION}

Diabetes mellitus (DM) is a chronic metabolic disease that occurs when the human body produces insufficient insulin or because cells do not respond to the produced insulin. ${ }^{1}$ Diabetes mellitus is a significant contributor to morbidity and mortality worldwide. $^{2}$ The number of people with DM is increasing due to population growth, aging, urbanization, increasing prevalence of obesity, and physical inactivity. The global prevalence of DM among adults over 18 years of age has risen from $4.7 \%$ in 1980 to $8.5 \%$ in 2014 , and it is estimated that, in 2040, 1 in 10 adults will suffer from DM. ${ }^{3}$ As the prevalence of degenerative lumbar diseases is also increasing, a higher number of patients with concomitant DM and degenerative lumbar disease would refer to spine surgeons for lumbar spine decompression and fusion in future.

Previous studies on patients with degenerative lumbar disease have shown lower pain improvement and higher incidence of postoperative complications in patients with DM comparing to non-DM subjects. ${ }^{4-6}$ As the possible explanation, irreversible nerve damage due to microvascular changes in DM patients has been reported in the literature. ${ }^{7,8}$ Therefore, it is suggested that decompression in DM patients may not have the same effect as in those who are not diabetic. ${ }^{9}$ In addition, a higher rate of postoperative complications and substantial morbidity and mortality is reported in DM patients who underwent spine surgery. ${ }^{10}$ All these make the spine surgery of DM patients with lumbar degenerative disease challenging. Determining the risk 
factors for spine surgery complications in DM patients could help with educational purposes and would result in new preventive policies at clinical and surgical guidelines.

To our knowledge, there is no prospective study comparing the outcomes of lumbar fusion surgery in patients with and without DM. The aim of this study was to assess whether the presence of diabetes in patients undergoing lumbar fusion surgery is associated with worse patient-reported outcomes, lower fusion rate, and more complications.

\section{MATERIAL AND METHODS}

This prospective study was conducted in Shariati Hospital (an academic and educational hospital affiliated with Tehran University of Medical Sciences) between March 2014 and March 2015. Two groups of patients who were candidates for spine instrumentation and fusion were enrolled. Group 1 consisted of patients with diabetes. All patients with a fasting blood glucose screen exceeding $126 \mathrm{mg} / \mathrm{dL}$ or with $\mathrm{HbA1C}$ higher than $6.5 \%$ were considered diabetic, even in the absence of a known history of treated or untreated diabetes (based upon the World Health Organization diagnostic criteria for diabetes), including both insulin-dependent and independent patients. ${ }^{11}$ All patients who entered into this group had history of diabetes, and all of them were on medication. Group 2 consisted of patients without diabetes who were age- and sex-matched with Group 1. Inclusion criteria were as follows: the need for spine instrumentation and fusion because of canal stenosis, disc herniation with instability, and degenerative spondylolisthesis. Data regarding age, duration of diabetes, comorbidities, fasting blood sugar (FBS), HbA1c, polyneuropathy, insulin dependence, duration of operation and the amount of bleeding, the number of infused packed cell, and duration of hospitalization were recorded for all patients. All patients with DM underwent electrodiagnostic studies (EMG-NCV).

Decompression and 1-level posterolateral fusion was performed using pedicle screws and a local bone graft. Great care was taken to ensure adequate decortication of the transverse processes and lateral facet surfaces. Bilateral facet fusion was performed in all patients. Local bone was generated from the decompression site lamina. No additional biologic materials were used for spinal fusion. All participants were examined by a neurosurgeon before the surgery, and 2 weeks, 6 months, and 1 year after
Table 1. Baseline patient and operative characteristics.

\begin{tabular}{lccc}
\hline & $\begin{array}{c}\text { Diabetic } \\
(\mathbf{n}=\mathbf{4 8})\end{array}$ & $\begin{array}{c}\text { Nondiabetic } \\
(\mathbf{n}=\mathbf{4 8})\end{array}$ & $\boldsymbol{P}$ Value \\
\hline Age (y) & $59.5 \pm 8.4$ & $56.1 \pm 7.7$ & .04 \\
Sex & $20(41.7 \%)$ & $16(34 \%)$ & .4 \\
$\quad$ Male & $28(58.3 \%)$ & $32(66 \%)$ & \\
$\quad$ Female & $3.8 \pm 0.9$ & $3.4 \pm 0.8$ & .02 \\
Duration of operation (h) & $5.5 \pm 3.4$ & $4.6 \pm 1.7$ & .09 \\
Duration of hospitalization (d) & & & \\
Comorbidity & $27(56.2 \%)$ & $10(20.8 \%)$ & .01 \\
$\quad$ HTN & $7(14.5 \%)$ & $3(6.2 \%)$ & \\
IHD & $2(4 \%)$ & $1(2 \%)$ & \\
RA & 0 & $1(2 \%)$ & \\
Hypothyroidism & $29(60.4 \%)$ & NA & \\
Polyneuropathy & $18(37.5 \%)$ & NA & \\
Insulin dependent & \multicolumn{3}{c}{} \\
\hline
\end{tabular}

Abbreviation: NA, not available.

that, and isometric muscle force of lower extremities were recorded before and 1 year after the surgery. We also asked our patients to fill out a valid and reliable Persian version of the Oswestry Disability Index $(\mathrm{ODI})^{12}$ and rate their pain by means of the visual analogue scale (VAS) before the operation, 2 weeks, 6 months, and 1 year postoperation. Lumbar computed tomography scan and lateral and anteroposterior $\mathrm{x}$-ray were obtained 1 year after the surgery to evaluate fusion. Bone fusion was defined as bridging bone remodeling across the transverse processes between the adjacent vertebrae.

All data were analyzed using SPSS software (version 20; SPSS Inc, Chicago, Illinois). Data were presented as mean $\pm \mathrm{SD}$ for continuous or frequencies for categorical variables. Independent sample $t$ test was used for comparison of continuous variables. Logistic regression by considering fusion as independent variable and patient group, age, bleeding volume, duration of hospitalization, preoperative ODI, and perioperative VAS as independent variables were done. A $P$ value less than .05 was considered as significant.

\section{RESULTS}

Forty-eight cases in the diabetic group and 48 in the control group were recruited. Basic patient information is presented in Table 1. Among the subjects of the diabetic group, the mean duration of diabetic disease, FBS, and Hb1Ac were $9.2 \pm 5.8$ years, $143.7 \pm 19.9 \mathrm{mg} / \mathrm{dL}$, and $7.5 \pm 0.7$, respectively.

After 1-year follow up, fusion rate was $53 \%$ in the DM group and $78 \%$ in the control group $(P=$ $.02)$. Our data showed no significant relationship between the fusion rate and the FBS level of diabetic 
Table 2. Comparison of different VAS and ODI scores between the 2 groups.

\begin{tabular}{lccr}
\hline & Diabetic & Nondiabetic & $P$ Value \\
\hline Pre-operation ODI & $67.6 \pm 10.4$ & $55.1 \pm 15.7$ & $<.001$ \\
Pre-operation VAS & $7.8 \pm 0.9$ & $7.1 \pm 1.1$ & .002 \\
ODI 2 wk postoperation & $54.3 \pm 12.9$ & $40.8 \pm 13.4$ & $<.001$ \\
VAS 2 wk postoperation & $5.4 \pm 1.5$ & $4.4 \pm 1.6$ & .003 \\
ODI 6 mo postoperation & $45.5 \pm 13.7$ & $34.7 \pm 12.8$ & $<.001$ \\
VAS 6 mo postoperation & $4.2 \pm 1.8$ & $3.6 \pm 1.5$ & .08 \\
ODI 1 y postoperation & $40.7 \pm 15.4$ & $31.5 \pm 12.5$ & .002 \\
VAS 1 y postoperation & $3.5 \pm 2$ & $2.9 \pm 1.3$ & .07 \\
Lumbar fusion & $28(58.3 \%)$ & $38(79.1 \%)$ & .02 \\
Pre-operation force/5 & $1(2.1 \%)$ & & .2 \\
3-4 & $2(4.2 \%)$ & & \\
3 & $6(12.5 \%)$ & & \\
4 & $39(81.3 \%)$ & & \\
Intact & & & \\
Force of lower limbs at 1 y & & & \\
postsurgery & $4(8.3 \%)$ & $3(6.2 \%)$ & .08 \\
Improved & $41(85.4 \%)$ & $44(91.6 \%)$ & \\
Unchanged & $3(6.2 \%)$ & $1(2 \%)$ & \\
Deteriorated &
\end{tabular}

Abbreviations: ODI, Oswestry Disability Index; VAS, visual analogue scale.

patients who underwent fusion surgery (142.5 \pm 19.5 versus $145.3 \pm 20.9, P=.6)$.

Comparing the outcome measurements of the study, we found that, except VAS scores at 6 months and 1 year after surgery, all other scores were significantly different between the 2 groups. Patients in the DM group had higher ODI scores comparing to controls (Table 2). Complications were not significantly different between the 2 groups (Table 3). Bleeding was significantly higher in the diabetic group. After 1 year of follow up, ODI and VAS were not significantly different postoperation between diabetic patients with or without polyneuropathy $(P=.1$ and .1 , respectively). As it is shown in Table 4 of the study, there was no difference between the ODI and VAS of DM patients with or without dependency to insulin, after 1-year follow up. Table 5 shows the complication rate of insulindependent and nondependent patients who underwent surgery.

Table 3. Comparison of complications between diabetic and nondiabetic patients.

\begin{tabular}{lccl}
\hline & Diabetic & Nondiabetic & $P$ Value \\
\hline Bleeding (mL) & $556.2 \pm 255$ & $428.1 \pm 182.7$ & .006 \\
Infused packed cell & $1.1 \pm 0.4$ & $1 \pm 0.2$ & .6 \\
Root damage & 0 & $2(4 \%)$ & .5 \\
Cerebral vascular accident & $1(2 \%)$ & 0 & \\
Pelvic pain & 0 & $1(2 \%)$ & \\
Decrease of isometric motor force & $1(2 \%)$ & 0 & \\
Need for reoperation & $1(2 \%)$ & 0 & \\
Wound infection & $7(14.5 \%)$ & $5(10.4 \%)$ & \\
Dural tear & $4(8 \%)$ & $3(6.2 \%)$ & \\
Postoperation hematoma & 0 & $1(2 \%)$ & \\
Thromboembolism & 0 & $1(2 \%)$ & \\
\hline
\end{tabular}

Table 4. Comparison between insulin-dependent and nondependent groups.

\begin{tabular}{lccl}
\hline & $\begin{array}{c}\text { Insulin } \\
\text { Dependent } \\
(\mathbf{N}=\mathbf{1 8})\end{array}$ & $\begin{array}{c}\text { Insulin } \\
\text { Independent } \\
(\mathbf{N}=\mathbf{3 0})\end{array}$ & $\boldsymbol{P}$ Value \\
\hline FBS & $149.2 \pm 16$ & $140.3 \pm 21.5$ & .1 \\
HbA1C & $7.9 \pm 0.8$ & $7.3 \pm 0.6$ & .006 \\
Duration of hospitalization & $6 \pm 2.6$ & $5.3 \pm 3.8$ & .4 \\
Pre-operation ODI & $72.1 \pm 8.7$ & $65 \pm 10.5$ & .02 \\
Pre-operation VAS & $8.1 \pm 0.9$ & $7.6 \pm 0.9$ & .1 \\
ODI 2 wk postoperation & $58.6 \pm 12.1$ & $51.8 \pm 12.9$ & .07 \\
VAS 2 wk postoperation & $5.8 \pm 1.5$ & $5.1 \pm 1.5$ & .1 \\
ODI 6 mo postoperation & $50.8 \pm 12.3$ & $42.3 \pm 13.6$ & .03 \\
VAS 6 mo postoperation & $4.8 \pm 1.6$ & $3.9 \pm 1.8$ & .06 \\
ODI 1 yr postoperation & $45 \pm 14.1$ & $38.1 \pm 15.8$ & .1 \\
VAS 1 yr postoperation & $3.9 \pm 1.8$ & $3.3 \pm 2$ & .3 \\
Lumbar fusion & $10(55.5 \%)$ & $18(60 \%)$ & .7 \\
\hline
\end{tabular}

Abbreviations: FBS, fasting blood sugar; ODI, Oswestry Disability Index; VAS, visual analogue scale.

\section{DISCUSSION}

According to this study, the fusion rate was significantly higher in nondiabetic cases than in diabetic ones ( 79 versus $58 \%, P=.02$ ). Oswestry Disability Index scores were also significantly higher in diabetic patients; however, it was only different in the pre-operation period and 6 months after the operation. In agreement with our results, Guzman et al reported the fusion rates in controlled diabetics, noncontrolled diabetics, and nondiabetic patients as 55, 47, and 54\%, respectively. ${ }^{13}$ They also found a significantly greater rate of fusion revisions in uncontrolled diabetic cases than in controlled diabetics or nondiabetics. ${ }^{13}$ In another study, Glassman et al evaluated 94 diabetics (51 noninsulin-dependent, and 43 insulin-dependent patients) with 43 controls who were matched for demographic characteristics. Nonunion rates were higher in insulin-dependent diabetes $(26 \%)$ than in noninsulin-dependent diabetes $(22 \%)$ and controls $(5 \%) .{ }^{14}$ Also, Armaghani et al compared 434 diabetics and 571 nondiabetics who underwent

Table 5. Comparison of complications between insulin-dependent and nondependent cases.

\begin{tabular}{lcc}
\hline & $\begin{array}{c}\text { Insulin } \\
\text { Dependent } \\
(\mathbf{N}=\mathbf{1 8})\end{array}$ & $\begin{array}{c}\text { Insulin } \\
\text { Independent } \\
(\mathbf{N}=\mathbf{3 0 )}\end{array}$ \\
\hline Root damage & $1(2 \%)$ & $1(2 \%)$ \\
CVA & 0 & $1(2 \%)$ \\
Pelvic pain & NA & NA \\
Decrease of motor force & 0 & $1(2 \%)$ \\
Need for reoperation & $1(2 \%)$ & 0 \\
Wound infection & $3(6 \%)$ & $4(8 \%)$ \\
Dura rupture & $2(4 \%)$ & $2(4 \%)$ \\
Postoperation hematoma & NA & NA \\
Thromboembolism & $\mathrm{NA}$ & $\mathrm{NA}$ \\
\hline
\end{tabular}

Abbreviation: NA, not available. 
elective spine surgery. They reported higher ODI and Numeric Rating Scale for pain in diabetic patients. $^{15}$

In the current study, the mean VAS was significantly higher in diabetic patients before operation and 2 weeks after operation. These findings show that diabetic patients who undergo spine fusion surgeries will suffer from nonunion, pain, and disability more than non-DM ones.

Diabetes mellitus is a multi-organ disease with a prevalence of near 300 million adults in 2010, which is estimated to reach 439 million adults in $2030 .{ }^{16}$ Diabetes-related complications may cause multiorgan system failures, and consequently, adverse surgery outcomes. ${ }^{16}$ Previous studies reported higher rates of surgical site infections, nonunion, and extended length of stay in patients with diabetes who underwent spine surgery. ${ }^{1,17-20}$ The rate of complications in the current study was $29 \%$ in diabetic patients. Bendo et al evaluated 32 diabetic cases who underwent spine surgery and reported the complication rate as $31 \% .^{21}$ Glassman et al found complications in $53 \%$ of patients with noninsulindependent diabetes and $56 \%$ of patients with insulin-dependent DM, while this rate was $21 \%$ in control group. ${ }^{14}$ Evaluating 23 adults with noninsulin-dependent diabetes, Cho et al reported that diabetes was not a significant risk factor for perioperative complications in spine surgery. ${ }^{22}$ Similarly, in another study on patients undergoing lumbar spine decompression, the outcome and improvement in symptoms were similar in diabetic and nondiabetic patients. ${ }^{23}$ Thus, there are controversies regarding the role of diabetes in developing perioperative complications. Insulin dependence is also a challenging issue in this area. Reviewing the literature, insulin dependence is considered to increase the risk of postoperative complications, ie, length of hospital stay and readmission. ${ }^{24}$ In the current study, the rate of wound infection was similar in noninsulin-dependent DM and insulindependent DM groups. Furthermore, the rate of complications between insulin-dependent and nondependent cases were not significantly different in the current study, while according to other studies, insulin-dependent DM patients had 1.9 times higher risk of wound infection than noninsulin-dependent DM patients. ${ }^{1,17,18,25,26}$

Diabetes is considered to be related to longer duration of surgery and hospitalization. Previous studies confirmed that diabetes led to increase of the length of stay in lumbar fusion patients. ${ }^{12,15}$ Golinvaux et al reported long hospitalization (more than 5 days) following elective lumbar fusion in $14.9 \%$ of nondiabetic, $20.1 \%$ of insulin-independent, and $26 \%$ of insulin-dependent patients. ${ }^{24}$ In our study, the duration of hospitalization was neither significantly different between diabetic and nondiabetic patients nor between insulin-dependent and independent ones. These controversies could be due to different sample sizes, heterogeneous inclusion and exclusion criteria, and different treatment protocols. As another possible complication, higher rate and volume of blood transfusion is reported in diabetic cases, although our data showed no significant difference between diabetic and nondiabetic patients.

A list of limitations regarding the methodology and interpretation of the data of this study could be mentioned. First, it was conducted in a tertiary referral hospital, and our patients could not be representative of the whole society. Second, the sample size was relatively small, with different surgical indications and comorbidities. This could affect the outcome of the study. Third, more assessment time points and longer follow-up period are required to clarify the accurate surgical outcome and define the surgical cautions in diabetic patients who undergo spinal fusion surgery.

\section{CONCLUSIONS}

Rate of fusion among diabetic patients who undergo lumbar spinal fusion surgery is lower than healthy controls. This could be considered by spine surgeons to provide the best possible facilities during the surgery to increase the fusion rate in these patients.

\section{REFERENCES}

1. Browne JA, Cook C, Pietrobon R, Bethel MA, Richardson WJ. Diabetes and early postoperative outcomes following lumbar fusion. Spine (Phila Pa 1976). 2007;32(20):224-2219.

2. Engelgau MM, Geiss LS, Saaddine JB, et al. The evolving diabetes burden in the United States. Ann Intern Med. 2004;140(11):945-50.

3. World Health Organization (WHO). Global Report on Diabetes. Geneva: WHO; 2016.

4. Satake K, Kanemura T, Matsumoto A, Yamaguchi H, Ishikawa Y. Predisposing factors for surgical site infection of spinal instrumentation surgery for diabetes patients. Eur Spine J. 2013;22(8):1854-1858.

5. Takahashi S, Suzuki A, Toyoda H, et al. Characteristics of diabetes associated with poor improvements in clinical 
outcomes after lumbar spine surgery. Spine (Phila Pa 1976). 2013;38(6):516-522.

6. ter Gunne AFP, Hosman AJ, Cohen DB, et al. A methodological systematic review on surgical site infections following spinal surgery: part 1: risk factors. Spine (Phila $\mathrm{Pa}$ 1976). 2012;37(24):2017-2033.

7. Freedman MK, Hilibrand AS, Blood EA, et al. The impact of diabetes on the outcomes of surgical and nonsurgical treatment of patients in the spine patient outcomes research trial. Spine (Phila Pa 1976). 2011;36(4):290.

8. Kim H-J, Moon S-H, Kim H-S, et al. Diabetes and smoking as prognostic factors after cervical laminoplasty. Bone Joint J. 2008;90(11):1468-1472.

9. Appaduray SP, Lo P. Effects of diabetes and smoking on lumbar spinal surgery outcomes. $J$ Clin Neurosci. 2013;20(12):1713-1717.

10. Kirkland KB, Briggs JP, Trivette SL, Wilkinson WE, Sexton DJ. The impact of surgical-site infections in the 1990s: attributable mortality, excess length of hospitalization, and extra costs. Infect Control Hosp Epidemiol. 1999;20(11):725-730.

11. World Health Organization. About diabetes. http:// www.who.int/diabetes/action_online/basics/en/index $2 . \mathrm{html}$. Accessed August 15, 2018.

12. Mousavi SJ, Parnianpour M, Mehdian H, Montazeri A, Mobini B. The Oswestry Disability Index, the Roland-Morris Disability Questionnaire, and the Quebec Back Pain Disability Scale: translation and validation studies of the Iranian versions. Spine (Phila Pa 1976). 2006;31(14):E454-E459.

13. Guzman JZ, Iatridis JC, Skovrlj B, et al. Outcomes and complications of diabetes mellitus on patients undergoing degenerative lumbar spine surgery. Spine (Phila Pa 1976). 2014;39(19):1596-1604.

14. Glassman SD, Alegre G, Carreon L, Dimar JR, Johnson JR. Perioperative complications of lumbar instrumentation and fusion in patients with diabetes mellitus. Spine J. 2003;3(6):496501 .

15. Armaghani SJ, Archer KR, Rolfe R, Demaio DN, Devin CJ. Diabetes is related to worse patient-reported outcomes at two years following spine surgery. J Bone Joint Surg Am. 2016;98(1):15-22.

16. Wukich DK. Diabetes and its negative impact on outcomes in orthopaedic surgery. World J Orthop. 2015;6(3):331-339.

17. Hikata $\mathrm{T}$, Iwanami A, Hosogane $\mathrm{N}$, et al. High preoperative hemoglobin Alc is a risk factor for surgical site infection after posterior thoracic and lumbar spinal instrumentation surgery. J Orthop Sci. 2014;19(2):223-238.

18. Chaichana KL, Bydon M, Santiago-Dieppa DR, et al. Risk of infection following posterior instrumented lumbar fusion for degenerative spine disease in 817 consecutive cases: clinical article. J Neurosurg Spine. 2014;20(1):45-52.
19. Walid MS, Newman BF, Yelverton JC, Nutter JP, Ajjan M, Robinson JS. Prevalence of previously unknown elevation of glycosylated hemoglobin in spine surgery patients and impact on length of stay and total cost. J Hosp Med. 2010;5(1):E10-E4.

20. Walid MS, Zaytseva N. How does chronic endocrine disease affect cost in spine surgery? World Neurosurg. 2010;73(5):578-581.

21. Bendo J, Spivak J, Moskovich R, Neuwirth $M$. Instrumented posterior arthrodesis of the lumbar spine in patients with diabetes mellitus. Am J Orthop (Belle Mead NJ). 2000;29(8):617-620.

22. Cho W, Lenke LG, Bridwell KH, et al. Comparison of spinal deformity surgery in patients with non-insulin-dependent diabetes mellitus (NIDDM) versus controls. Spine (Phila Pa 1976). 2012;37(16):E978-E984.

23. Cinotti G, Postacchini F, Weinstein J. Lumbar spinal stenosis and diabetes. Outcome of surgical decompression. Bone Joint J. 1994;76(2):215-219.

24. Golinvaux NS, Varthi AG, Bohl DD, Basques BA, Grauer JN. Complication rates following elective lumbar fusion in patients with diabetes: insulin dependence makes the difference. Spine (Phila Pa 1976). 2014;39(12):1809-1816.

25. Campbell PG, Yadla S, Malone J, et al. Complications related to instrumentation in spine surgery: a prospective analysis. Neurosurg Focus. 2011;31(4):E10.

26. Chen S, Anderson MV, Cheng WK, Wongworawat MD. Diabetes associated with increased surgical site infections in spinal arthrodesis. Clin Orthop Relat Res. 2009;467(7):1670 1673.

Disclosures and COI: The authors received no funding for this study and report no conflicts of interest.

Corresponding Author: Morteza FaghihJouibari, MD, Assistant Professer of Neurosurgery, Shariati Hospital, Tehran University of Medical Sciences, Jalal-Al-Ahmad Street, Tehran, Iran. Phone: +98-2184901, Fax: +98-2188633039; Email: mortezafaghihj@gmail.com.

Published 31 August 2018

This manuscript is generously published free of charge by ISASS, the International Society for the Advancement of Spine Surgery. Copyright (c) 2018 ISASS. To see more or order reprints or permissions, see http://ijssurgery.com. 